\title{
Exploring nurses' knowledge of basic life support guideline of American Heart Association: a local study
}

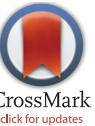

\author{
Payman Asadi $^{\circledR}$, Seyyed Mahdi Zia Ziabari, Vahid Monsef-Kasmaei* ${ }^{\circledR}$ \\ Guilan Road Trauma Research Center, Guilan University of Medical Sciences, Rasht, Iran
}

\begin{abstract}
Received: 10 February 2021
Accepted: 1 May 2021

Published online: 16 May 202

*Corresponding author: Vahid Monsef-Kasmaei, MD Guilan Road Trauma Research Center, Poursina Hospital, Namjoo Street, Rasht, Iran. Postal Code: 41937-13194.

TELFAX: 01333368773

Email: infogtrcir@gmail.com

Competing interests: None

Funding information: None.

Citation: Asadi P, Zia Ziabari SM, Monsef-Kasmaei V. Exploring nurses knowledge of basic life support guideline of American Heart Association: a local study. Journal of Emergency Practice and Trauma 2021; 7(2): 106-110. doi: 10.34172/ jept.2021.02.
\end{abstract}

\begin{abstract}
Objective: Awareness of the changes concerning the clinical guidelines for cardiopulmonary resuscitation (CPR) is essential for nurses. This study aimed at assessing the nurses' knowledge of the 2015 American Heart Association basic life support guideline algorithm.

Methods: In a cross-sectional study, the knowledge of 183 nurses working in emergency departments, intensive care unit (ICU) and coronary care unit (CCU) regarding the 2015 American Heart Association basic life support guideline algorithm was investigated. Data were collected by a 20-item questionnaire regarding the knowledge needed for resuscitation operations as well as the identification of the early stages of cardiac arrest. Nurses with a score of 10 and less were put in the poor group, 11-15 in the fair group, and score of more than 15 in the good group.

Results: Results showed that the highest percentage of the right answer was observed in questions $20(98.4 \%), 11(93.4 \%)$, and $1(88 \%)$, while the lowest percentage of the correct answer was found in questions $13(30.6 \%), 2(31.1 \%)$, and $3(32.8 \%)$. Mean \pm SD of knowledge score was $12.3 \pm 2.2$. A statistically significant difference was observed between knowledge of ICU nurses with an experience of basic life support educational course and those with no experience of such education. The knowledge score of educated and noneducated nurses was $11.5 \pm 2.2$ and $13.2 \pm 2.5$, respectively.

Conclusion: This study indicated that ICU nurses do not have enough knowledge about basic life support of the 2015 American Heart Association guideline. Development of knowledge is one of the important components of professional expansion in nursing education programs.

Keywords: Knowledge, Nurse, Basic Cardiac Life Support
\end{abstract}

Introduction

Sudden cardiac arrest is a remarkable cause of death in many parts of the world, notwithstanding the significant developments in medical equipment (1). Sudden cardiac arrest is a medical emergency leading to cardiac death if not immediately treated. In fact, a quick and appropriate medical measure can lead to the survival of the patient (2). Cardiopulmonary resuscitation (CPR) has been emphasized in several studies in different countries which can reduce mortality by up to $50 \%$ (3).

Nurses are generally the first responders to a heart disorder in hospitals, and the first actions are taken by them $(4,5)$. Therefore, they must first conduct basic life support (BLS) without losing time. In recent years, nursing education has focused on theoretical education, and a profound gap has been developed between theoretical and clinical education. Many nursing researchers reported that nursing students did not have enough skills in clinical settings despite having the right theoretical knowledge (6). The educational needs of nurses should be determined and evaluated on a regular basis in order to continue the assessment and effectiveness of the training (7). Dal and Sarpkaya in a study on evaluation of the effects of CPR education found that nursing students forgot the theoretical concepts of CPR and applied programs after several months (8). Consequently, nurses must be involved in BLS educational programs, and these programs should be updated at regular intervals with new guidelines. This study aimed at investigating the knowledge of the emergency, intensive care unit (ICU) and coronary care unit (CCU) nurses of Rasht teaching hospitals concerning the 2015 AHA BLS guideline algorithm.

\section{Methods}

In this cross-sectional study, we investigated the knowledge of 183 nurses working in emergency departments, ICU, and CCU of Rasht teaching hospitals concerning the 2015 American Heart Association BLS guideline algorithm in 2016. The census sampling method was used. Data were collected by a two-part questionnaire. The content 
validity ratio (CVR) and content validity index (CVI) of the questionnaire were assessed by using the opinions of 10 experts. The CVR of all questions was greater than 0.62. Also, CVI was examined in three dimensions of relevance, simplicity and clarity. The lowest CVI was 0.7 and the highest was 1. Questions with a CVI ranging from 0.7 to 0.8 were partially reviewed, and other questions were high as CVI remained unchanged. Finally the CVI of all questions were more than 0.8 . The first part of the questionnaire included demographic information such as age, sex, education level, job experience, BLS algorithm training, and workplace. The second part encompassed 20 multiple-choice questions regarding the knowledge needed for resuscitation operations as well as the identification of the early stages of cardiac arrest. The questionnaire was distributed among participants by one of the members of our research team. Each question had only one correct answer. The correct answer was assigned score 1 and the wrong answer did not get a score. Therefore, nurses' knowledge was assessed based on the score between 1 and 20. The nurses with a score of 10 or less were put in the poor group, nurses with 11-15 in the fair group, and nurses with a score more than 15 in the good group. Incomplete questionnaires were excluded from the study. Finally, the collected data were entered into SPSS software version 21. Data were analyzed using Mann-Whitney, Kruskal-Wallis, and Spearman correlation coefficient tests $(P$ value $<0.05$ was considered significant).

\section{Results}

The present study included mostly women working in the emergency department. Mean and standard deviation of age were $31 \pm 5$ years ( $\min 22$ and max 46 years). The highest frequency was recorded for those with a bachelor's degree and a mean job experience of 6.49 years. Most participants in the study had an experience of learning the BLS algorithm and were averagely trained $(1.5 \pm 2.1)$ (Table $1)$.

Results of this study showed that most nurses were in the intermediate level of knowledge, and individuals with low and high knowledge were in the next ranks.

Table 2 depicts that the highest percentage of the right answer was observed in questions 20 (98.4\%), 11 (93.4\%) and $1(88 \%)$, while the lowest percentage of the correct answer was seen in questions 13 (30.6\%), 2 (31.1\%), and $3(32.8 \%)$. The mean and standard deviation of the knowledge score was $12.3 \pm 2.2$. The lowest and highest scores were 7 and 17 , respectively (Table 2 ).

The statistical tests of Mann-Whitney, KruskalWallis, and Spearman correlation coefficient showed no statistically significant difference between the knowledge score and demographic variables in the present study $(P>0.05)$.

On the other hand, Table 3 shows a statistically significant difference between the knowledge of ICU nurses with an experience of BLS educational course and those with no experience of such education. The knowledge score of educated and non-educated nurses was $11.5 \pm 2.2$ and $13.2 \pm 2.5$, respectively.

\section{Discussion}

The results of our study showed that most nurses were in the intermediate fair level of knowledge. According to the 2015 American Heart Association BLS guideline in both hospital and pre-hospital phases, chain of survival of cardiac arrest in adults, prompt diagnosis of cardiac arrest, rapid activation of emergency medical services, faster $\mathrm{CPR}$ and defibrillation as soon as possible are used for improving the survival chance (9). Theoretical knowledge and practical skills of BLS are important determinants of successful CPR technique. BLS techniques are very easy and even ordinary people should be aware of them. Due to the benefits of CPR, advanced countries have implemented its education even for high school students since some decades ago (10).

BLS educational programs should be inevitably conducted for nurses in hospitals and the effectiveness of these programs needs to be properly monitored. It is critically important for nurses to know the latest update of medical guidelines and have the suitable practical skills along with the theoretical knowledge.

AHA only issues a BLS card for people with a written test score of $\geq 84 \%$. In the current study, we considered the score $\geq 80$ as a high score. According to this formula, only $6 \%$ of the people had the acceptable information, and the majority of participants had moderate information. The most common wrong answers were given to questions about the exact location of massage in adults and the

Table 1. Demographic Characteristics of the Studied Samples

\begin{tabular}{|c|c|c|c|}
\hline & & Number & Percent \\
\hline \multirow{2}{*}{ Sex } & Woman & 164 & 89.6 \\
\hline & Man & 19 & 10.4 \\
\hline \multirow{4}{*}{ Age group (y) } & $<25$ & 32 & 17.5 \\
\hline & $25-30$ & 72 & 39.3 \\
\hline & $30-35$ & 44 & 24.0 \\
\hline & $>35$ & 35 & 19.1 \\
\hline \multirow{2}{*}{ Education } & Bachelor's degree & 174 & 95.1 \\
\hline & Master's degree & 9 & 4.9 \\
\hline \multirow{4}{*}{ Job experience (y) } & $<2$ & 37 & 20.2 \\
\hline & $2-5$ & 56 & 30.6 \\
\hline & $5-10$ & 56 & 30.6 \\
\hline & $>10$ & 34 & 18.6 \\
\hline \multirow{2}{*}{$\begin{array}{l}\text { BLS algorithm education } \\
\text { experience }\end{array}$} & Yes & 97 & 53.0 \\
\hline & No & 86 & 47.0 \\
\hline \multirow{3}{*}{ Workplace } & Emergency department & 106 & 57.9 \\
\hline & $\mathrm{ICU}$ & 58 & 31.7 \\
\hline & $\mathrm{CCU}$ & 19 & 10.4 \\
\hline
\end{tabular}




\begin{tabular}{|c|c|c|c|c|}
\hline & \multicolumn{2}{|c|}{ Incorrect } & \multicolumn{2}{|c|}{ Correct } \\
\hline & No. & $\%$ & No. & $\%$ \\
\hline A 50-year-old man has suffered from a retrosternal chest discomfort, severe sweating, and vomiting. What is the next step? & 3 & 1.6 & 180 & 98.4 \\
\hline What is the speed of chest massage in adults and children during CPR? & 12 & 6.6 & 171 & 93.4 \\
\hline What does BLS stand for? & 22 & 12 & 161 & 88 \\
\hline How deep is the chest compression in adults during CPR? & 30 & 16.4 & 153 & 83.6 \\
\hline What is the ratio of CPR in adults when the rescuer is alone? & 42 & 23 & 141 & 77 \\
\hline A baby has suddenly suffered from a choking. You make sure he/she is not able to cry or cough. What is your first reaction? & 42 & 23 & 141 & 77 \\
\hline How do you do life-saving breathing in newborns? & 49 & 26.8 & 134 & 73.2 \\
\hline If you do not want to have mouth-to-mouth CPR, all of the following can be done except: & 51 & 27.9 & 132 & 72.1 \\
\hline How deep is the chest compression in children during CPR? & 59 & 32.2 & 124 & 67.8 \\
\hline $\begin{array}{l}\text { Your colleague has suddenly suffered from an interrupted speech and a weak right upper extremity. Which of the following could } \\
\text { happen? }\end{array}$ & 68 & 37.2 & 115 & 62.8 \\
\hline What does AED stand for? & 74 & 40.4 & 109 & 59.6 \\
\hline What does EMS stand for? & 87 & 47.5 & 96 & 52.5 \\
\hline Where is the chest compression in adults? & 90 & 49.2 & 93 & 50.8 \\
\hline Where is the chest compression in newborns? & 95 & 51.9 & 88 & 48.1 \\
\hline $\begin{array}{l}\text { What will be your first reaction if you and your friend are eating food in a diner and suddenly there are signs of choking in your } \\
\text { friend? }\end{array}$ & 100 & 54.6 & 83 & 45.4 \\
\hline $\begin{array}{l}\text { An adult has been immersed in freshwater with no response and has left it. He has breathing on his own, but without a response. } \\
\text { What is the first step? }\end{array}$ & 101 & 55.2 & 82 & 44.8 \\
\hline How deep is the chest compression in newborns during CPR? & 105 & 57.4 & 78 & 42.6 \\
\hline If you are sure that someone will not respond to you even after shaking and calling him/her. What will your immediate action be? & 123 & 67.2 & 60 & 32.8 \\
\hline What will be your first reaction when you find an unconscious person with no response on road? (Note: You are only there) & 126 & 68.9 & 57 & 31.1 \\
\hline What is the chest massage and ventilation ratio in a newborn? & 127 & 69.4 & 56 & 30.6 \\
\hline
\end{tabular}

Table 3. Comparison of the Knowledge Scores of Emergency, ICU, and CCU Nurses Based on the Educational Course

\begin{tabular}{|c|c|c|c|c|c|c|c|}
\hline Workplace & & $\mathbf{N}$ & Mean & SD & Minimum & Maximum & $P$ \\
\hline \multirow{3}{*}{ Emergency department } & Yes & 52 & 12.2115 & 2.19032 & 7.00 & 17.00 & \multirow{3}{*}{0.64} \\
\hline & No & 54 & 12.4630 & 2.10760 & 8.00 & 17.00 & \\
\hline & Total & 106 & 12.3396 & 2.14204 & 7.00 & 17.00 & \\
\hline \multirow{3}{*}{ ICU } & Yes & 33 & 11.5152 & 2.16681 & 8.00 & 16.00 & \multirow{3}{*}{0.01} \\
\hline & No & 25 & 13.2400 & 2.50466 & 7.00 & 17.00 & \\
\hline & Total & 58 & 12.2586 & 2.45350 & 7.00 & 17.00 & \\
\hline \multirow{3}{*}{$\mathrm{CCU}$} & Yes & 12 & 12.9167 & 1.56428 & 10.00 & 15.00 & \multirow{3}{*}{0.10} \\
\hline & No & 7 & 11.4286 & 1.98806 & 9.00 & 15.00 & \\
\hline & Total & 19 & 12.3684 & 1.83214 & 9.00 & 15.00 & \\
\hline
\end{tabular}

number of chest massages in children and adults. Alsayil et al showed that $44 \%$ of the participants did not know the exact location of the chest compression in adults, and $68.8 \%$ were not aware of the exact location of the chest compression of the infants (11). It seems that doing chest massages properly in the right place increases the likelihood of coronary circulation and reduces the risk of associated complications such as fracture. In addition, the high number of incorrect responses about the basic principle of the BLS is worrying.

All previous studies in assessing the knowledge and attitudes of health care providers in the BLS have indicated that staff information is poor (12-20). The effective factors included lack of interest in learning and updating their educational materials, time constraint and extremely intensive work schedules due to manpower shortage in many state hospitals of Iran, insufficiency of equipment such as advanced mannequins to train resuscitation skills due to being expensive, lack of appropriate teaching materials for pre-training study, forgetting the acquired knowledge over time, lack of job experience in newly employed staff in ICU, and the absence of any mandatory regulations for the BLS certification in the nurses, possibly due to lack of educational staff, work space and suitable 
educational equipment. Therefore, such an educational program needs to be replaced in the curriculum.

This study found a statistically significant difference between the scores of the knowledge of the nurses who completed the BLS educational course and that of the nurses who did not complete this course. Therefore, the knowledge score of educated nurses was unexpectedly less compared to the second group. On the contrary, the results of the study by Yunus et al were inconsistent with our results. In this regard, the mean score of knowledge and practice of educated nurses was higher compared to those with no education, and this difference was statistically significant. However, the knowledge and practice score of a significant number of educated nurses was lower than the mean (21).

Non-practical education on mannequins, the time constraint, and forgetting the gained knowledge over time (22) can justify the low score in trained nurses. Therefore, continuous and systematic strategies for education with practical exercises are needed to keep the team performance in a good situation for caring cardiovascular and pulmonary arrest to prevent possible mistakes. $\mathrm{Da}$ Costa and colleagues have shown that continuous education serves as a tool for updating healthcare. They stated that attending classes with long hours can have a negative effect on the learning capacity and should be replaced with several educational classes at different times (23).

Our study had some limitations. Firstly, we only considered the level of nurses' knowledge. Due to the wide range of hospitals and the large number of study samples, their attitude and practice were not reviewed. Secondly, the teaching hospitals were specialized. For example, Poursina hospital is a trauma center, Razi hospital is an internal and infectious diseases center, and Heshmat hospital is a cardiology center. Therefore, the knowledge of ICU staff in Heshmat hospital was higher than that in other hospitals in the study investigating the relationship between the knowledge score and the type of hospital. It is important to mention that it was impossible to assimilate hospitals in terms of their specialty due to the limited number of hospitals. The last but not least, we only included nurses of three out of eight teaching hospitals in Rasht. Hence, the results of this study cannot be generalized to the whole society.

In order to improve knowledge and skills, frequent education is needed. Therefore, nurses must firstly acquire knowledge and skills about the BLS with regular planning at universities. Furthermore, these educational programs should be repeated at regular intervals and be updated in accordance with the guidelines during working periods.

\section{Conclusion}

The results of this study showed that the majority of emergency nurses as well as ICU and CCU nurses had average algorithms in Rasht teaching hospitals. The improvement of knowledge is one of the important components of professional development in nursing educational programs. Nurses are required to have knowledge and skills about the BLS because they have a key role in the healthcare team and the initial treatment of patients with cardiac arrest.

\section{Authors' Contribution}

We thank Guilan Road Trauma Research Center, Guilan University of Medical Sciences, Rasht, Iran.

\section{Ethical issues}

This study was approved by the Ethics Committee of Guilan University of Medical Sciences (IR.GUMS. REC.1395.212).

\section{References}

1. Travers AH, Rea TD, Bobrow BJ, Edelson DP, Berg RA, Sayre MR, et al. Part 4: CPR overview: 2010 American Heart Association guidelines for cardiopulmonary resuscitation and emergency cardiovascular care. Circulation 2010; 122(18 Suppl 3): S676-84. doi: 10.1161/ circulationaha.110.970913.

2. Sasson C, Rogers MA, Dahl J, Kellermann AL. Predictors of survival from out-of-hospital cardiac arrest: a systematic review and meta-analysis. Circ Cardiovasc Qual Outcomes 2010; 3(1): 63-81. doi: 10.1161/circoutcomes.109.889576.

3. Huikuri HV, Castellanos A, Myerburg RJ. Sudden death due to cardiac arrhythmias. N Engl J Med 2001; 345(20): 147382. doi: 10.1056/NEJMra000650.

4. Abella BS, Sandbo N, Vassilatos P, Alvarado JP, O'Hearn $\mathrm{N}$, Wigder HN, et al. Chest compression rates during cardiopulmonary resuscitation are suboptimal: a prospective study during in-hospital cardiac arrest. Circulation 2005; 111(4): 428-34. doi: 10.1161/01.cir.0000153811.84257.59.

5. Goswami R, Kanika, Sembian N. Effectiveness of the training program on knowledge and practices regarding Basic Life Support (BLS) among nursing students. Int J Clin Anesthesiol 2015; 3(2): 1046.

6. Terzi B, Polat Ş, Düzkaya DS. Evaluation of basic life support training program provided for nurses in a university hospital. Int J Med Res Health Sci 2017; 6(6): 70-6.

7. Kol E, İlaslan E, Turkay M. Training needs of clinical nurses at an university hospital in Turkey. Nurse Educ Pract 2017; 22: 15-20. doi: 10.1016/j.nepr.2016.11.004.

8. Dal U, Sarpkaya D. Knowledge and psychomotor skills of nursing students in North Cyprus in the area of cardiopulmonary resuscitation. Pak J Med Sci 2013; 29(4): 966-71. doi: 10.12669/pjms.294.3450.

9. Travers AH, Perkins GD, Berg RA, Castren M, Considine J, Escalante R, et al. Part 3: adult basic life support and automated external defibrillation: 2015 international consensus on cardiopulmonary resuscitation and emergency cardiovascular care science with treatment recommendations. Circulation 2015; 132(16 Suppl 1): S5183. doi: 10.1161/cir.0000000000000272.

10. Hazinski MF, Markenson D, Neish S, Gerardi M, Hootman J, Nichol G, et al. Response to cardiac arrest and selected life-threatening medical emergencies: the medical 
emergency response plan for schools: a statement for healthcare providers, policymakers, school administrators, and community leaders. Circulation 2004; 109(2): 278-91. doi: 10.1161/01.cir.0000109486.45545.ad.

11. Alsayil SN, Alzahran SM, Alhawiti WM. Awareness of basic life support among medical and nursing students at Tabuk University. Basic Res J Med Clin Sci 2016; 5(3): 53-7.

12. Rajeswaran L, Cox M, Moeng S, Tsima BM. Assessment of nurses' cardiopulmonary resuscitation knowledge and skills within three district hospitals in Botswana. Afr J Prim Health Care Fam Med 2018; 10(1): e1-e6. doi: 10.4102/ phcfm.v10i1.1633.

13. Chandrasekaran S, Kumar S, Bhat SA, Saravanakumar, Shabbir PM, Chandrasekaran V. Awareness of basic life support among medical, dental, nursing students and doctors. Indian J Anaesth 2010; 54(2): 121-6. doi: 10.4103/0019-5049.63650.

14. Mohan M, Sharma SM, Shetty T, Gupta P. Awareness of basic life support (BLS) among dental interns and dental practitioners. Journal of Health and Allied Sciences NU 2015; 5(3): 14-8. doi: 10.1055/s-0040-1703905.

15. Zamir Q, Nadeem A, Rizvi AH. Awareness of cardiopulmonary resuscitation in medical-students and doctors in Rawalpindi-Islamabad, Pakistan. J Pak Med Assoc 2012; 62(12): 1361-4.

16. Almesned A, Almeman A, Alakhtar AM, AlAboudi AA, Alotaibi AZ, Al-Ghasham YA, et al. Basic life support knowledge of healthcare students and professionals in the Qassim University. Int J Health Sci (Qassim) 2014; 8(2): 141-50. doi: 10.12816/0006080.

17. Aroor AR, Saya RP, Attar NR, Saya GK, Ravinanthanan M.
Awareness about basic life support and emergency medical services and its associated factors among students in a tertiary care hospital in South India. J Emerg Trauma Shock 2014; 7(3): 166-9. doi: 10.4103/0974-2700.136857.

18. Baduni N, Prakash P, Srivastava D, Sanwal MK, Singh BP. Awareness of basic life support among dental practitioners. Natl J Maxillofac Surg 2014; 5(1): 19-22. doi: 10.4103/09755950.140159.

19. Alotaibi O, Alamri F, Almufleh L, Alsougi W. Basic life support: knowledge and attitude among dental students and Staff in the College of Dentistry, King Saud University. Saudi J Dent Res 2016; 7(1): 51-6. doi: 10.1016/j.sjdr.2015.06.001.

20. Narayan DP, Biradar SV, Reddy MT, Bk S. Assessment of knowledge and attitude about basic life support among dental interns and postgraduate students in Bangalore city, India. World J Emerg Med 2015; 6(2): 118-22. doi: 10.5847/ wjem.j.1920-8642.2015.02.006.

21. Yunus M, Mishra A, Karim HM, Raphael V, Ahmed G, Myrthong CE. Knowledge, attitude and practice of basic life support among junior doctors and students in a tertiary care medical institute. Int J Res Med Sci 2015; 3(12): 364450. doi: 10.18203/2320-6012.ijrms20151416.

22. Fernandes JM, Leite AL, Auto Bde S, Lima JE, Rivera IR, Mendonça MA. Teaching basic life support to students of public and private high schools. Arq Bras Cardiol 2014; 102(6): 593-601. doi: 10.5935/abc.20140071.

23. da Costa DB, Vannuchi MT, Haddad MC, Cardoso MGP, da Silva LG, Garcia SD. Custo de educação continuada para equipe de enfermagem de um hospital universitário público. Rev Eletrônica Enferm. 2012;14(2):257-66. 